ORIGINAL ARTICLE

\title{
Frequency of Stillbirths in Obese Pregnant Women
}

\author{
KIRAN JAVED ${ }^{1}$, RAZIA BIBI ${ }^{2}$, SAMINA GOHAR ${ }^{3}$, MUNAWAR AFZAL ${ }^{4}$ \\ ${ }^{1}$ Postgraduate Resident (PGR) Department of Obstetrics and Gynecology, Lady Reading Hospital, Peshawar \\ ${ }^{2}$ Assistant Professor of Gynecology and Obstetrics Department, KIMS Medical College, Kohat \\ ${ }^{3}$ Senior Registrar, Gynecology and Obstetrics Department Sahara Medical College, Narowal \\ ${ }^{4}$ Associate Professor Obstetrics and Gynecology Department, Sahara Medical College, Narowal \\ Correspondence to: Dr. Kiran Javed; Email: kiranjaved2010@gmail.com, Ph; +9203345654582
}

\begin{abstract}
Objective: To determine the frequency of stillbirths in obese pregnant women.

Design of the Study: It's a descriptive cross-sectional study.

Study Settings: This study was carried out at Department of Obstetrics and Gynecology, Lady Reading Hospital Peshawar from January 2018 to July 2018.

Material and Methods: In this study a total of 289 patients were observed. Detailed history was taken from each patient, period of gestation was calculated from 1st trimester scan, conducted by a person having at least 2 years post-graduate training experience in his/her respective field. Height/Weight measurements were done by the same standardized equipment's for all enrolled patients and BMI calculation done by standard WHO formula before delivery. Baby after delivery was examined and looked for presence/absence of vital signs by the designated obstetrician. Outcome of pregnancy either alive or stillborn baby was recorded for each patient in order to fulfill the objective of study. To control bias and confounding, exclusion criteria had strictly followed. All the data was recorded on a pre-designed Proforma and subjected to analysis.

Results of the Study: Our study shows that mean age of $28.87+3.92$ years Forty two percent patients were primi gravid and $58 \%$ patients were multi gravida. Forty three percent patients were primi para while $57 \%$ patients were multi para. Ninety percent babies were alive while $10 \%$ babies were still birth.

Conclusion: Our study concludes that the frequency of still births was $10 \%$ in obese pregnant women.

Keywords: still births, obese, pregnant women, primi para, WHO.
\end{abstract}

\section{INTRODUCTION}

The proportion of women with overweight or obesity in early pregnancy is continuously increasing in the world. The problem with obesity has reached pandemic proportions. $^{1,2}$ Increasing body mass index (BMI) is associated with increased risks of complications during fertilization, implantation, pregnancy, delivery and the postpartum period. The risks are increased for both mother and child in the short-term as well as in the long-term perspective. The fetus can be affected by an increased risk of congenital defects and macrosomia. ${ }^{3}$

In countries with scarce health resources, stillbirth is a biggest problem. At the same time, it is also a major public health issue in high resource countries. Majority of the perinatal deaths of stillbirth are associated with $22^{\text {nd }}$ week of gestation. ${ }^{4}$ Global burden of stillbirths is 3.2 million per annum which is almost equal to annual neonatal deaths annually which is 3.0 million. Frequency of still birth is very high in low-income countries of the world. ${ }^{5}$ Among high income countries, its prevalence is very high in the United Kingdom and United States. In 2006, about 26000 stillbirths were reported in the USA that comes to 6.1 out of 1000 live births while in UK it was about 3800 with ratio of 5.2 per live birth. ${ }^{6}$ Globally, Pakistan was among countries with highest still births during the year 2015 that was 43.1 still births per 1000 total births while during that year its global burden was 18.4 per 1000 total births. ${ }^{7}$ Despite of a matter of high concern, the matter of still births remained an unrecognized issue in many counters across the globe and Pakistan as well. ${ }^{8}$

However, in high resource countries, a drastic decrease has been seen in its prevalence as low as 5 per 1000 stillbirths and it remained very low to the tune of 3 -
$4 / 1000$ total births. But, in the same regime frequency of neonatal mortality declined with fast speed; resulting into increase in proportion of still births. ${ }^{9}$

Ratio of still births in Pakistan is $36-98$ per 1000 live births. Stillbirth is associated with many risk factors among them some common and highly affecting factors are maternal disorders (diabetes and pre-eclampsia), maternal infection during pregnancy, foetal growth restrictions, complications related with child birth and congenital abnormalities. ${ }^{10}$ Moreover, the ratio of deliveries at home is about two-third of total deliveries and about $62 \%$ of deliveries are handled by untrained birth attendants. ${ }^{10}$ In this nexus, another factor is base of majority of researches was based at hospitals having major focus on neonatal and maternal deaths with least interest in stillbirths. ${ }^{11,12}$

With the increased ratio of complications in pregnancies which is added up by obesity, rate of stillbirths is very high and it is imperative to develop a screening strategy on obese population. The aim of the present study was to determine the frequency of stillbirths in obese pregnant women. Stillbirth is under-researched despite its high incidence, compared to other pregnancy complications. Due to scarcity of data on this so far neglected issue and increasing load of patents with stillbirths locally, findings of the study should be seen as impetus for more refined studies that will potentially offer answers to many questions emanating from these preliminary efforts.

\section{MATERIAL AND METHODS}

Before starting the study permission from Institutional Ethical Committee was obtained. This study was carried out at Department of Obstetrics and Gynecology, Lady 
Reading Hospital Peshawar from January 2018 to July 2018. The study design was descriptive cross-sectional. As maternal obesity may be linked for $25 \%$ of stillbirths (literature review), choosing to calculate sample size from WHO sample size calculation where $\mathrm{P}=25 \%$, Confidence Interval $=95 \%$, Margin of error $(a)=5 \%$, total sample size $=$ 289. For data collection non-probability (consecutive) sampling method was used. Pregnant women who delivered in the unit of study, singleton 24+ onwards POG, aged between 18-40 years, Parity $<7$, Having BMI of $>25 \mathrm{~kg} / \mathrm{m}^{2}$ were included in this study. Additional deliveries were conducted by an obstetrician of the unit of study having at least 2 years post graduate experience in her respective field. Pregnant women with multifetal pregnancies, women with diabetes/hypertension and sequalae, pregnancies affected by congenital anomalies with poor prognosis were excluded. Patients in whom delivery is complicated by APH, cord prolapse, prolonged labour or maternal accident were also excluded.

\section{STUDY RESULTS}

Analysis of age of participants of the study shows that 121 (42\%) patients belonged to age group 18-30 years while $168(58 \%)$ patients were in age range $31-40$ years out of total 289 patients. Mean age of $28.87+3.92$ years. Gestational age among 289 patients was $13 \%$ patients were at pre term, 208(72\%) patients were at term while $43(15 \%)$ patients were at post term. Status of BMI among 289 patients was analyzed as $237(82 \%)$ patients had BMl range $24-30 \mathrm{Kg} / \mathrm{m}^{2}$ while $52(18 \%)$ patients had $\mathrm{BMI}$ range $31-36 \mathrm{Kg} / \mathrm{m}^{2}$. Mean BMl of $28.93+1.82 \mathrm{Kg} / \mathrm{m}^{2}$. Status of gravidity among 289 patients was analyzed as $121(42 \%)$ patients were primi gravida while $168(58 \%)$ patients were multi gravida. Status of race among 289 patients was analyzed as all patients had no rmak race $289(100 \%)$. Status of education level among 289 patients was analyzed as $87(30 \%)$ patients were educated while 202(70\%) patients were un-educated. Socioeconomic status among 289 patients was analyzed as $150(52 \%)$ patients were poor, 110 (38\%) patients were middle class and 29(10\%) patients were rich. Status of prenatal care among 289 patients was analyzed as $52(18 \%)$ patients had prenatal care, $237(82 \%)$ patients didn't had prenatal care. Status of smoking / other addiction among 289 patients was analyzed as none of the patients had the habit of Smoking / other addiction. Status of prior still birth among 289 patients was analyzed as $43(15 \%)$ patients had prior still birth, $246(85 \%)$ patients didn't had prior still birth. Status of height among 289 patients was analyzed as $223(77 \%)$ patients had height range 1.54-160 meters while 66(23\%) patients had height range 1.61-170 meters. Mean height $1.64 \pm 4.38$ meters. Status of weight among 289 patients was analyzed as $223(77 \%)$ patients had weight range $80-$ $100 \mathrm{kgs}$ while $66(23 \%)$ patients had weight range 100-120 kgs. Mean weight $92.704 .70 \mathrm{kgs}$ status of mode of delivery among 289 patients was analyzed as 194(67\%) patients had NVD while 95(33\%) patients had C section. Status of baby weight among 289 patients was analyzed as 23(8\%) babies were LBW, 173(60\%) babies had normal weight while $93(32 \%)$ babies were a microsomia. Status of still birth among 289 patients was analyzed as 250(90\%) babies were alive while $29(10 \%)$ babies were born still birth.

Stratification of still birth with age, gravidity, and mode of delivery given in table no 2, 3, 4 \& 5

Table 1: Socio-demographics of different parameters

\begin{tabular}{|c|c|c|c|c|}
\hline Parameter & & \multicolumn{2}{|c|}{ Frequency } & Percentage \\
\hline \multirow[t]{2}{*}{ Age } & $18-30$ years & \multicolumn{2}{|c|}{121} & $42 \%$ \\
\hline & $31-40$ years & \multicolumn{2}{|l|}{168} & $58 \%$ \\
\hline \multirow[t]{4}{*}{ Gestational Age } & Pre term & \multicolumn{2}{|l|}{38} & $13 \%$ \\
\hline & Term & \multicolumn{2}{|l|}{208} & $72 \%$ \\
\hline & Post term & \multicolumn{2}{|l|}{43} & $15 \%$ \\
\hline & \multicolumn{3}{|c|}{$\begin{array}{l}\text { Mean gestational age }= \\
37.48 \pm 2.47 \text { weeks }\end{array}$} & \\
\hline \multirow{2}{*}{$\begin{array}{l}\text { Body Mass } \\
\text { Index BMI }\end{array}$} & $24-30 \mathrm{~kg} / \mathrm{m}^{2}$ & \multicolumn{2}{|l|}{237} & $82 \%$ \\
\hline & $31-36 \mathrm{~kg} / \mathrm{m}^{2}$ & \multicolumn{2}{|l|}{52} & $18 \%$ \\
\hline \multirow{2}{*}{$\begin{array}{l}\text { Gravida } \\
\text { Distribution }\end{array}$} & Pri migravida & \multicolumn{2}{|l|}{121} & $42 \%$ \\
\hline & Multi gravida & \multicolumn{2}{|l|}{168} & $58 \%$ \\
\hline Race/ Ethnicity & Normal & \multicolumn{2}{|l|}{100} & $100 \%$ \\
\hline \multirow{2}{*}{$\begin{array}{l}\text { Educational } \\
\text { Level }\end{array}$} & Educated & 87 & & $30 \%$ \\
\hline & Non-Educated & 202 & & $70 \%$ \\
\hline Socioeconomic & Poor & 150 & & $52 \%$ \\
\hline status & Middle Class & 110 & & $38 \%$ \\
\hline & Rich & 29 & & $10 \%$ \\
\hline Prenatal Care & Yes & 52 & & $18 \%$ \\
\hline & No & 237 & & $82 \%$ \\
\hline Smoking/Other & Yes & 0 & & $0 \%$ \\
\hline Addiction & No & 289 & & $100 \%$ \\
\hline Prior Still Birth & Yes & 43 & & $15 \%$ \\
\hline & No & 246 & & $85 \%$ \\
\hline Height & $1.54-1.60$ meters & 223 & & $77 \%$ \\
\hline & 1.61-1.71meteres & 266 & & $23 \%$ \\
\hline & Mean height $=1.64$ & & & \\
\hline Weight & $80-100 \mathrm{~kg}$ & 223 & & $77 \%$ \\
\hline & $100-120 \mathrm{~kg}$ & 266 & & $23 \%$ \\
\hline & Mean weight $=92 \pm 4$ & & & \\
\hline Mode of & NVD & & 194 & $67 \%$ \\
\hline Delivery & C-Section & & 95 & $33 \%$ \\
\hline Baby Weight & LBW & & 23 & $8 \%$ \\
\hline & Normal & & 173 & $60 \%$ \\
\hline & Macrosomia & & 93 & $32 \%$ \\
\hline Outcome & Alive & & 260 & $90 \%$ \\
\hline & Still Birth & & 29 & $10 \%$ \\
\hline
\end{tabular}

Table 2: Stratification of outcome with W.R.T. Age Distribution

\begin{tabular}{|l|l|l|l|}
\hline Outcome & $18-30$ years & $31-40$ years & Total \\
\hline Alive & 109 & 151 & 260 \\
\hline Still Birth & 12 & 17 & 29 \\
\hline Total & 121 & 168 & 289 \\
\hline
\end{tabular}

P-value was 0.9551 on Chi Square test.

Table 3 Data Stratification W.R.T Gravida

\begin{tabular}{|l|l|l|l|}
\hline Outcome & Primi gravida & Multi gravida & Total \\
\hline Alive & 109 & 151 & 260 \\
\hline Still birth & 12 & 17 & 29 \\
\hline Total & 121 & 168 & 289 \\
\hline
\end{tabular}

p-value was 0.9551on Chi Square Test

Table 4 Data Stratification W.R.T Mode of Delivery

\begin{tabular}{|l|l|l|l|}
\hline Outcome & NVD & C-Section & Total \\
\hline Alive & 175 & 85 & 260 \\
\hline Still birth & 19 & 10 & 29 \\
\hline Total & 194 & 95 & 289 \\
\hline
\end{tabular}

Chi Square test was applied in which p-value was 0.8456

\section{DISCUSSION}

At global level, ration of still births is very high in Pakistan and is a very alarming situation. ${ }^{13}$ This study showed high estimation of stillbirths to the tune of 18 per 1000 live births which is comparatively less as shown in published data for Pakistan. ${ }^{14,15}$ It may be associated with conduct of studies in tertiary care system and booking relevant cases only. 
However, it is worth mentioning here that there is three times increase in deliveries at hospitals where good antenatal and obstetrical care facilities have been provided during last two decades. Other countries having high ratio of still births also belong to developing regions and are India, Nepal and Bangladesh. ${ }^{16}$

Our study shows that mothers who delivered to still birth were age between 31 to 40 years. Our this finding is in line with Mustafa et al. (2016) ${ }^{12}$ who reported that maternal age was between 20-34 years who gave birth to still births (73.22\%). Likewise, findings were reported by researchers in Pakistan, India and Nepal. ${ }^{17,18,19}$ Contrary to it, in developed countires, still birth is highly associated with maternal age and old age has high frequency (>35 years) ${ }^{20,21}$

Rate of stillbirth is very high in primiparous mothers. Our study proved ratio of still briths to be $61 \%$ in primiparous mothers (61\%). However, this high frequency may be decreased by making early detection of risk factors in such mothers but owing to lack of best antenatal care facilties, such mothers have high chances of delivering stillbirth. ${ }^{22,23}$

In comparison, low risk of stillbirth in primiparous mothers has been reported from developed countries which may be due to well established infrastructure. ${ }^{10,20}$

Our study shows that at mean age of $28.87 \pm 3.92$ years. Forty two percent patients were primi gravid and $58 \%$ patients were multi gravida. In another study Secher et al.(2005) ${ }^{24}$ had reported that the frequency of still births was $8 \%$ in obese pregnant women in which majority of the women were in age 31-40 years, multigravida. ${ }^{24}$ Similar results were observed in another study conducted by Salihu et al.(2005) ${ }^{25}$ in which the incidence of still births in obese pregnant women was $10 \%$. Nohr et al. $(2005)^{26}$ had reported $12 \%$ incidence of still births in pregnant women.

Similar results were observed in another study conducted by Yao R et al. $(2014)^{27}$ in which the frequency of still births was $13 \%$ in obese pregnant women. Similar results were observed in another study conducted by Aune et al. (2014) ${ }^{28}$ in which the frequency of still births in obese pregnant women was $7 \%$.

\section{CONCLUSION}

Our study concludes that the frequency of still births was $10 \%$ in obese pregnant women.

\section{REFERENCES}

1. Flegal KM, Kruszon-Moran D, Carroll MD, Fryar CD, Ogden CL. Trends in obesity among adults in the United States, 2005 to 2014 Jama. 2016 Jun 7;315(21):2284-91.

2. Aune D, Saugstad OD, Henriksen T, Tonstad S. Maternal body mass index and the risk of fetal death, stillbirth, and infant death: a systematic review and meta-analysis. Jama. 2014 Apr 16;311(15):1536-46

3. Johansson S, Villamor E, Altman M, Bonamy AK, Granath $F$ Cnattingius $S$. Maternal overweight and obesity in early pregnancy and risk of infant mortality: a population based cohort study in Sweden. BMJ (Clinical research ed). 2014;349:g6572.

4. Lawn JE, Blencowe H, Waiswa P, Amouzou A, Mathers C, Hogan D, et al. Stillbirths: rates, risk factors, and acceleration towards 2030 Lancet (London, England). 2016;387(10018):587-603.

5. Bodnar LM, Ness RB, Markovic N, Roberts JM. The risk of preeclampsia rises with increasing prepregnancy body mass index. Ann Epidemiol. 2005 Aug;15(7):475-82
6. Jacob L, Kostev K, Kalder M. Risk of stillbirth in pregnant women with obesity in the United Kingdom. Obesity research \& clinical practice. 2016 Sep 1;10(5):574-9.

7. Blencowe H, Cousens S, Jassir FB, Say L, Chou D, Mathers C Hogan D, Shiekh S, Qureshi ZU, You D, Lawn JE, for the lancet stillbirth epidemiology investigator group. National, regional, and worldwide estimates of stillbirth rates in 2015, with trends from 2000: a systematic analysis. Lancet Global Health. 4:e98-108

8. Zakar MZ, Zakar R, Mustafa M, Jalil A, Fischer F. Underreporting of stillbirths in Pakistan: perspectives of the parents, community and healthcare providers. BMC Pregnancy and Childbirth. 2018 Dec;18(1):1-9.

9. Hales CM, Fryar CD, Carroll MD, Freedman DS, Ogden CL. Trends in Obesity and Severe Obesity Prevalence in US Youth and Adults by Sex and Age, 2007-2008 to 2015-2016. Jama. 2018.

10. Vogel JP, Souza JP, Mori R, Morisaki N, Lumbiganon P, Laopaiboon $M$, et al. Maternal complications and perinatal mortality: Findings of the World Health Organization Muticountry Survey on Maternal and newborn Health. BJOG. 2014;121(Suppl.1):76-88.

11. McClure EM, Sleem S, Goudar SS, Moore JL, Garces A, Esamai F, et al. Stillbirth rate in Low-middle income countries 2010-2013: a population based multi-country study from the Global Network. Reproductive Health. 2015;12(Supp12):57.

12. Mustufa MA, Kulsoom S, Sameen I, Moorani KN, Memon AA, Korejo R. Frequency of stillbirths in a tertiary care hospital, Karachi. Pakistan journal of medical sciences. 2016 Jan;32(1):91.

13. Hamid S, Malik AU, Richard F. Stillbirth -a neglected priority: Understanding its social meaning in Pakistan. J Pak Med Assoc. 2014;64(3):331-333.

14. McClure EM, Sleem S, Goudar SS, Moore JL, Garces A, Esamai F, et al. Stillbirth rate in Low-middle income countries 2010-2013: a population based multi-country study from the Global Network. Reproductive Health. 2015;12(Supp12):57.

15. Hashim N, Naqvi S, Khanam M, Jaffry HF. Primiparity is an intrapartum obstetric risk factor. J Pak Med Assoc. 2012;62(7):694698.

16. Yousfani S, Bibi S, Mumtaz F, Memon A, Khushk IA, Saeed F, Khan M. Perinatal Mortality and Related Obstetric Risk Factors at a Tertiary Care Hospital of Hyderabad. J Liaquat Uni Med Health Sci. 2008;7(4):204-207.

17. Jehan I, McClure EM, Salat S, Rizvi S, Pasha O, Harris $\mathrm{H}$, et al Stillbirths in an Urban Community in Pakistan. Am J Obstet Gynecol. 2007;197(3):257.e1-257.e8.

18. Hossain $\mathrm{N}$, Khan $\mathrm{N}$, Khan $\mathrm{NH}$. Obstetric causes of stillbirth at low socioeconomic settings. J Pak Med Assoc. 2009;59:744-747.

19. Tamrakar SR, Chawala CD. Intrauterine foetal death and its probable causes: Two years experience in Dhulikhel Hospital -Kathmandu University Hospital. Kathmandu Univ Med J. 2012;10:44-48.

20. Gordon A, Greenow RC, McGeechan K, Morris J, Jeffery H. Risk factors for antepartum stillbirth and the influence of maternal age in New South Wales Australia: A population based study. BMC Pregnancy and Childbirth. 2013;13:12. doi:10.1186/1471-2393-13-12.

21. Vogel JP, Souza JP, Mori R, Morisaki N, Lumbiganon P, Laopaiboon $\mathrm{M}$, et al. Maternal complications and perinatal mortality: Findings of the World Health Organization Muticountry Survey on Maternal and newborn Health. BJOG. 2014;121(Suppl.1):76-88.

22. Korejo R, Bhutta S, Noorani KJ, Bhutta ZA. An audit and trends of perinatal mortality at Jinnah Postgraduate Medical Center, Karachi. J Pak Med Assoc. 2007;57:168-172.

23. Avachat SS, Phalke DB, Phalke VD. Risk factors associated with stillbirths in the rural area of Western Maharashtra, India. Arch Med Health Sci. 2015;3:56-59.

24. Secher NJ. Prepregnancy weight and the risk of still birth and neonatal death. BGOJ. 2005;112:403-8.

25. Salihu HM, Dunlop AL, Hedayatzadeh M, Alio AP, Kirby RS, Alexander GR. Extreme obesity and risk of stillbirth among black and white gravidas. Obstetrics and gynecology. 2007;110(3):552-7.

26. Nohr EA. Bech BH, Davies MJ, Frydenberg M. Henriksen TB, Olsen J. Prepregnancy obesity and fetal death: a study within the Danish National Birth Cohort. Obstetrics and gynecology. 2005;106(2):250-9.

27. Yao R, Ananth CV, Park BY, Pereira L, Plante LA Obesity and the risk of stillbirth: a population-based culiuit study. American journal of obstetrics and gynecology. 2014;210(5):457.1-9.

28. Aune D, Saugstad OD, Henriksen T. Tonstad S. Maternal body mass index and the risk of fetal death, stillbirth, and infant death: a systematic review and meta analysis. Jama. 2014:311(75):1536-46. 